\title{
15
}

\section{Developing a Model for Basement Flood Relief Works for the New Millennium}

\author{
G. J. Steiss and W. D. Watters
}

Almost half of the City of Winnipeg is serviced by combined sewer systems. The service area is mainly in the older, core area of the City, and comprises approximately $10,500 \mathrm{ha}$. The combined sewer service area is partitioned into 42 individual sewer districts. Each district has its own lateral, collector and trunk sewer system with at least one river outfall.

The combined sewer systems were designed and built from the late 1800s, up to 1960 , and reflect the site conditions of the time. Since then increases in impervious area, such as paved parking lots, driveways and wider paved streets, have changed the district hydrology. This led to less stormwater infiltration and higher flows and volumes of runoffentering the combined sewer system. Consequently, the conveyance capacity of the sewer system is frequently exceeded, particularly in the older areas. This causes sewer surcharge and backup into basements, with resultant property damage and potential health risks.

The City of Winnipeg initiated a basement flood relief program in the mid1960 s to provide a minimum five-year level of protection to the residents. Since 1977 , this program has been developed with computer models based on various versions of the Stormwater Management Model (SWMM). To date, sewer relief works have been implemented in 21 of the City's combined sewer districts. These relief works have been carried out, for the most part, in isolation from other City initiatives. The current climate of fiscal responsibility, heightened public awareness and the introduction of new City infrastructure initiatives mandate a thoughtful and carefully planned program, fully cognizant of current and future planned development in all public sectors.

Steiss, G. and W.D. Watters. 2001. "Developing a Model for Basement Flood Relief Works for the New Millennium." Journal of Water Management Modeling R207-15. doi: 10.14796/JWMM.R207-15. (C) CHI 2001 www.chijournal.org ISSN: 2292-6062 (Formerly in Models and applications to Urban Water Systems. ISBN: 0-9683681-4-X) 


\subsection{Introduction}

This chapter describes an enhanced model for providing stormwater management to upgrade the level of basement flood protection in Winnipeg's combined sewer districts. A number of district studies have been carried out using SWMM to assess the current level of service and provide cost-effective programs to upgrade the level of service. These programs have all been developed to meet a clearly defined scope of work; however, the implementation of these projects requires the expenditure of considerable public funds. As such, the public's growing expectation of an integrated approach to infrastructure improvements results in a changing protocol for the basement flood relief program.

This does not change the basic requirement of the program to upgrade basement flood protection to a minimum five-year level of service. It does, however, mandate further investigation to integrate the program with other City infrastructure initiatives to develop an all-encompassing, cost-effective implementation program.

The following details the typical development of a basement flood relief program and suggests a model for enhancement and integration with other City initiatives. The analysis carried out for the Marion and Despins Combined Sewer Districts in the City of Winnipeg is described. It includes a review of the SWMM model verification, development and selection of the recommended relief works to provide a five-year level of service. It also details the steps, which can be taken to integrate the relief works with other new City initiatives for infrastructure renewal and the combined sewer overflow management. An integrated approach can provide the City with effective long-term solutions and least-cost economic benefits, while minimizing service disruption to the public.

\subsubsection{Marion and Despins Districts}

The Marion and Despins Combined Sewer Districts are centrally located in the City of Winnipeg on the east side of the Red River opposite the confluence of the Assiniboine River. Development in the districts began in the late 1800's, starting near the Red River and progressing east to the Seine River. The Marion District covers approximately 240 ha of drainage area. The Despins District is located immediately north of the Marion District and comprises approximately 110 ha of contributing area. The location of the Districts, with respect to the City and the overall combined sewer service area, is shown in Figure 15.1.

The Marion and Despins Districts are primarily residential, with commercial and some industrial development along the major thoroughfares. The overall district comprises: 


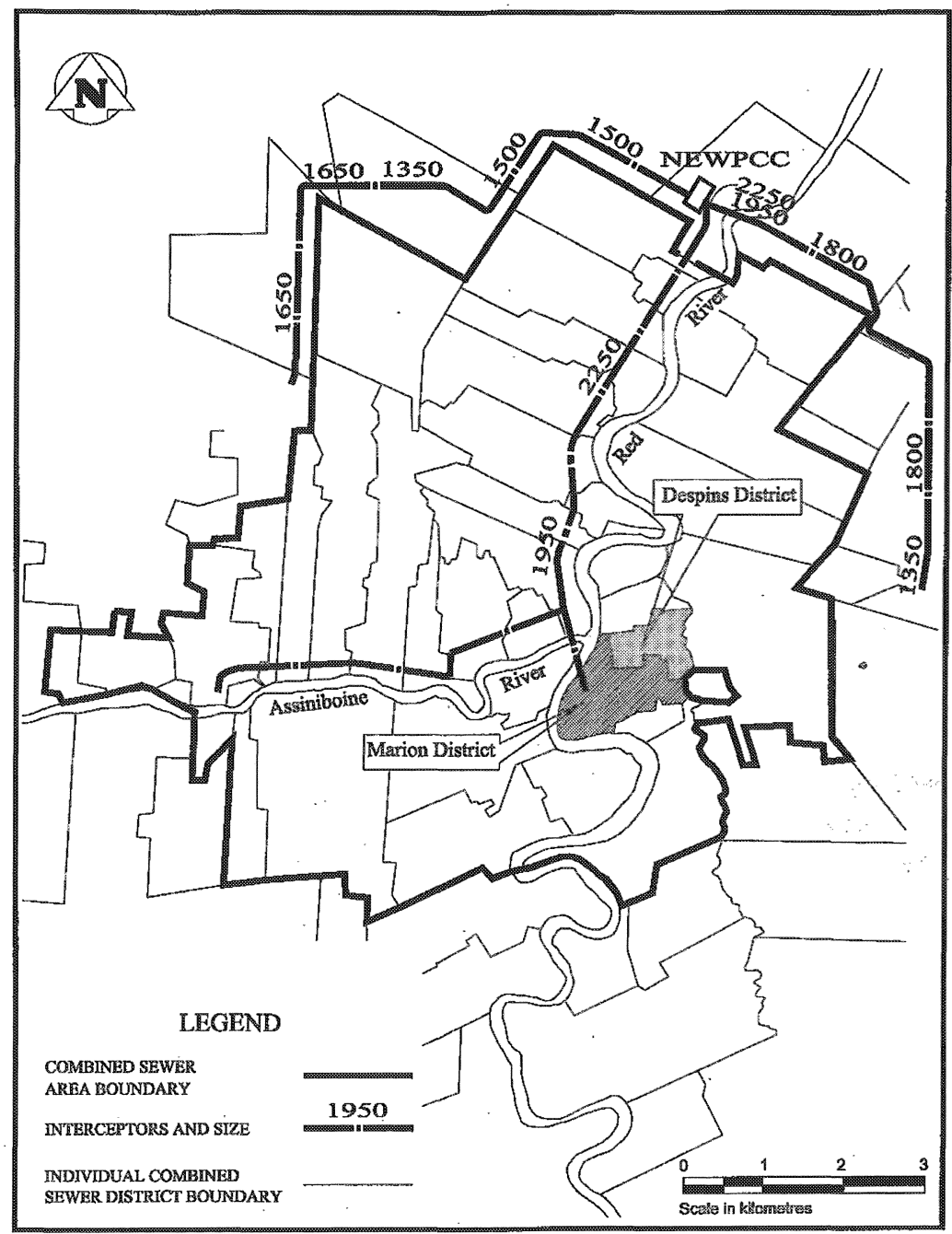

Figure 15.1 Winnipeg's combined sewer service area and location of Marion and Despins districts.

- $70 \%$ residential;

- $15 \%$ industrial and commercial;

- $10 \%$ green space; and

- $5 \%$ institutional.

The Marion and Despins Districts have been previously studied on two occasions. The City of Winnipeg carried out a preliminary analysis as part of a comprehensive review of combined sewer upgrading requirements to 
prioritize relief works (Girling and Sharp, 1986). An engineering consultant reviewed the two districts in detail, on an accelerated schedule, to consider sewer system improvements in conjunction with a major transportation project (RCPL, 1996). This latter work led to the implementation of relief works in conjunction with the roadway and bridge works. Wardrop Engineering was retained by the City of Winnipeg to review the previous studies and carry out preliminary design, detailed design and contract administration services for the implementation of the basement flood relief works.

\subsubsection{Combined Sewer System}

The combined sewer system consists of a network of lateral sewers that collect both sanitary sewage and stormwater runoff. The lateral sewers discharge to trunk sewers that convey the wastewater to weir diversions located near the rivers. Dry weather flows (DWF) and nominal wet weather flows (typically 2.75 times DWF) are diverted to the interceptor sewer system and conveyed

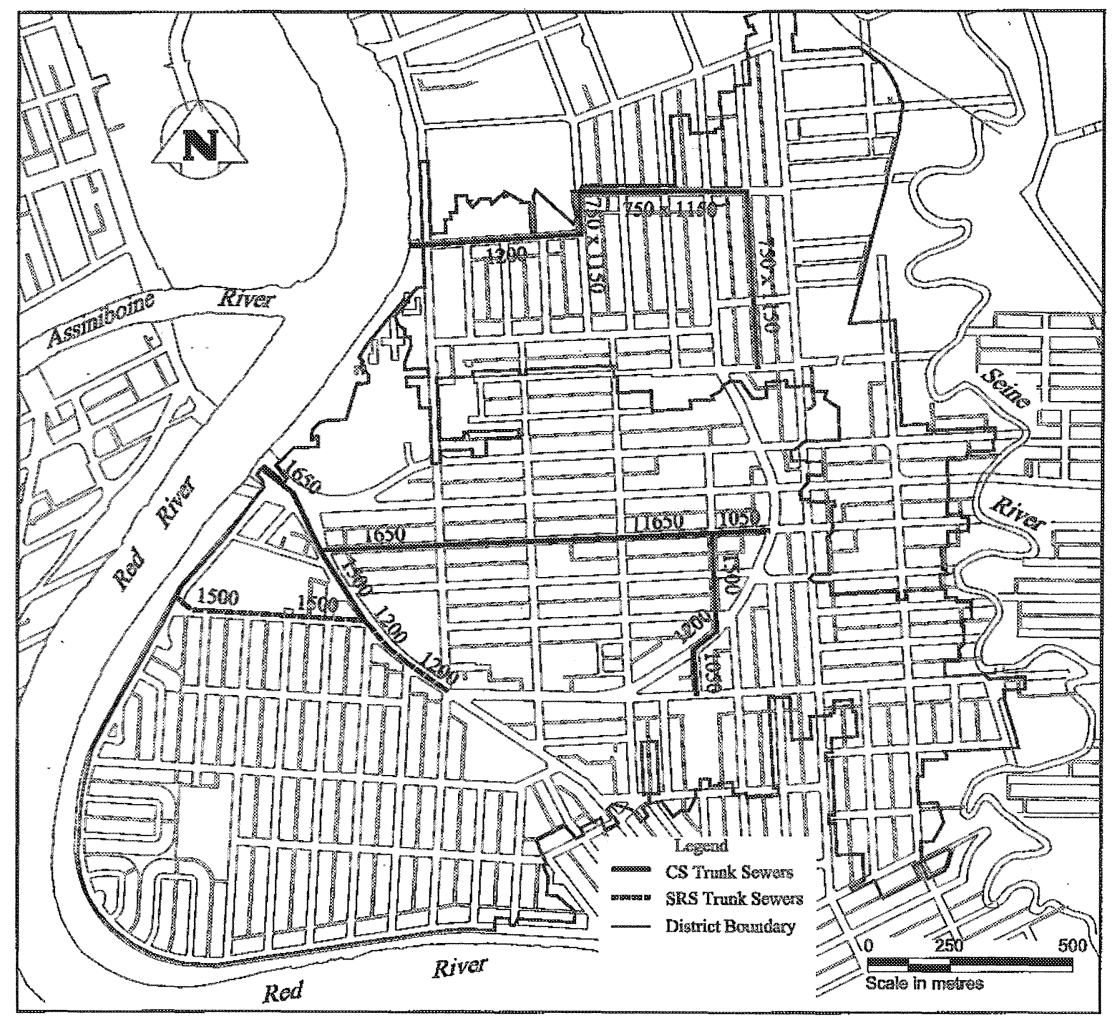

Figure 15.2 Marion and Despins districts - trunk sewer locations. 
to the City's North End Water Pollution Control Centre for treatment. Sewer flows exceeding the diversion capacity overflow the weir and are discharged to the rivers. This typically occurs eighteen times per warm weather season (May 1 to September 30) in the Marion and Despins Districts (Wardrop and Tetres, 1998).

The location and size of the existing trunk sewers, as well as the location of the overflows to the river, are shown in Figure 15.2. The figure also shows the relief trunk constructed in conjunction with the major transportation project in 1997.

\subsubsection{Basement Flood Relief Program}

The basement flood relief program was developed to upgrade the level of basement flood protection in the City. The guidelines for the program are to initially provide a minimum five-year level of basement flood protection to the combined sewer systems.

Basement flood relief works have been implemented in 21 of the City's 42 combined sewer districts. Implementation of relief works in the remaining districts will be prioritized based on the benefit/cost ratio of the recommended works. The cost to upgrade the sewer systems in the remaining districts is estimated to be $\$ 120$ million.

\subsection{Basement Flood Relief Analysis}

A typical combined sewer district basement flood relief program generally consists of the following major tasks:

- a monitoring program including flow and level recorders in the sewer system and, if necessary, a temporary rain gage to augment the City's network of continuous recording rain stations;

- SWMM model development, calibration and verification, and assessment of the existing level of basement flood protection;

- analysis of potential relief alternatives to upgrade the system, cost estimates for the works, and recommendation of the preferred alternative for implementation; and

- detailed design and construction of the relief works.

This discussion focuses on the preliminary aspects of the analysis (i.e. prior to detailed design) that formulate and define the final direction of the sewer relief works. 


\subsubsection{Model Verification}

As noted previously, a SWMM model of the Marion and Despins Sewer Districts had been developed and calibrated for use in conjunction with a prior major transportation project. This current project required a review of the previous calibration work, and verification of the model with additional monitored data collected in 1997 and 1998. The current model was revised to account for recent changes in the district since the original model development, which had occurred prior to the $1997 / 98$ system monitoring. The model verification essentially paralleled the tasks associated with typical model calibration and generally comprised:

- rainfall event screening;

- review of sewer response (monitoring data) to rainfall;

- selection of representative events for model verification;

- computer simulations; and

- comparison of model results to monitored data.

The rainfall event screening was carried out for all significant rainfall events that occurred in 1997 and 1998. Rainfall data from the three surrounding rain gages was collected and analysed for total depth of rainfall for each event. This initial screening was done to eliminate those events that had a great deal of variation over the districts.

The remaining rainfall events were analysed to compare rainfall intensities at the various stations, since a similar accumulation of rainfall is not necessarily indicative of the same rainfall pattern. This was accomplished by importing the raw rainfall data into the RainPak utility of PCSWMM and comparing the rainfall hyetographs developed for each station. Rainfall events with similar rainfall patterns were selected for use in the verification analysis. A sample hyetograph is shown on Figure 15.3. The level of detail used in the screening process provided a great deal of confidence in the rainfall data, as the SWMM model is most sensitive to this parameter in estimating the volume of runoff (Huber and Dickenson, 1988).

The next step was to compare the sewer response to the rainfall data. This was done to weed out any obviously erroneous or misleading monitoring data. This is a time saving procedure considering the severe environment the monitors are installed in, and the tendency for malfunction under wet weather flow conditions. The remaining data after the screening process provided seven wet weather events for model verification, four in 1997, and three in 1998. A sample comparison is shown on Figure 15.4.

Verification consisted of routing the selected events through the model and comparing the computed flow levels to the monitored data. The model provided generally good results at most sewer monitoring locations. The model was 


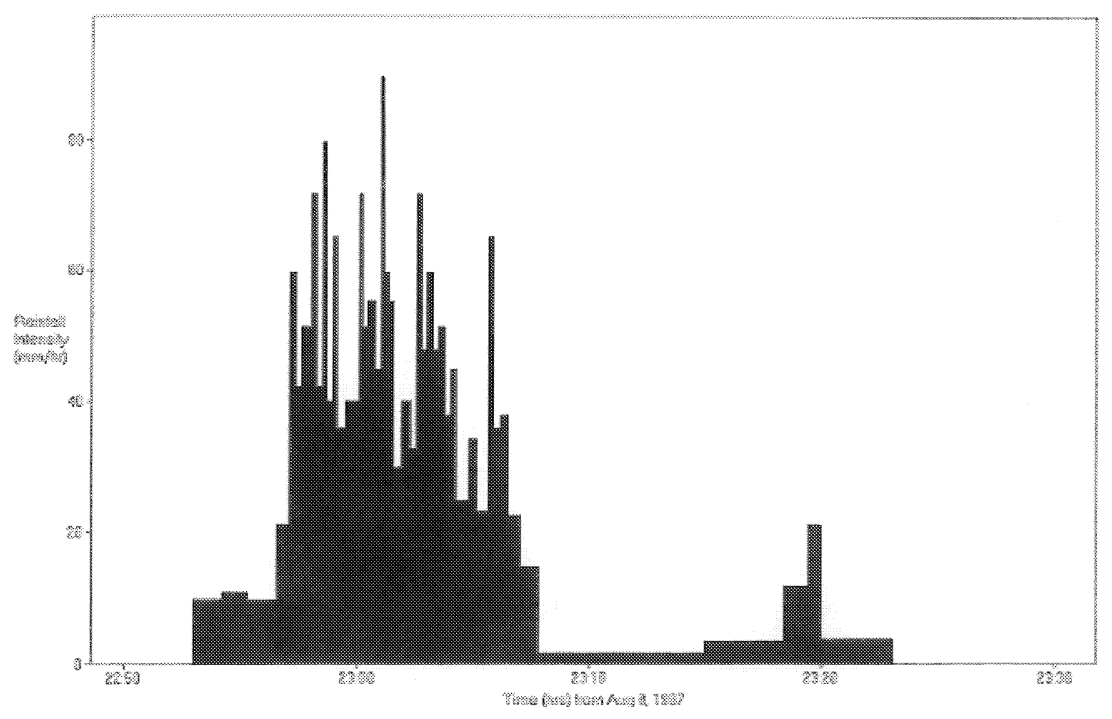

Figure 15.3 Rainfall hyetograph from PCSWMM Rainpak utility.

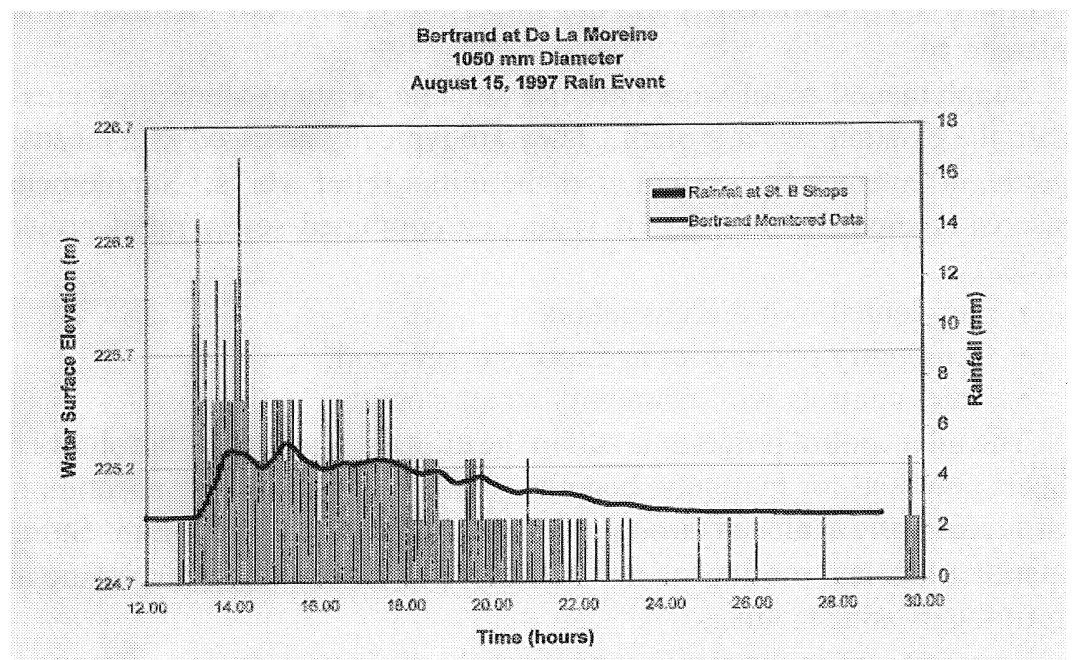

Figure 15.4 Comparison of sewer response to rainfall..

representative of the combined sewer systems response to rainfall and showed that additional calibration work was not warranted. 


\subsubsection{Review of Potential Relief Measures}

The development of a comprehensive flood relief program requires an extensive analysis of the various stormwater management measures. The basic objective is to control stormwater runoff to reduce sewer surcharging to acceptable levels and to minimize the cost of relief sewers. The review of basement flood relief works in the City of Winnipeg typically consists of an analysis of major and supplemental relief measures. The major relief measures typically involve piping installations such as:

- stormwater separation: installing new land drainage sewers to reduce stormwater flows to the combined sewer system. Typically done on a selective basis to match the conveyance capacity of the combined sewer.

- wastewater separation: installing new wastewater sewers to service existing residences which essentially converts the combined sewer system into a land drainage or separate stormwater system.

- storm relief sewers: installing parallel relief pipes to augment the capacity of the combined sewer system.

The installation of storm relief sewers has historically proved the most cost-effective relief measure, and not surprisingly, has been the most widely implemented.

Supplemental relief works are not suitable as stand-alone measures to update the existing sewer system. They are typically assessed as a means to upgrade, or enhance the system after the initial relief works. Supplemental measures studied for the City of Winnipeg combined sewer relief projects include:

- residential roof disconnection;

- temporary parking lot and roof storage; and,

- inlet controls with temporary street storage.

The inlet control program is still in the pilot program stage, but shows the greatest potential for hydraulic benefits. Residential roof disconnection has been successfully achieved through a homeowner education program. Storage on parking lots and rooftops is not viable due to difficulties in accessing and retrofitting existing facilities.

The first step in the review of potential relief measures in a district is to review the topography. Unlike most combined sewer districts in the City, the Marion and Despins Districts are bounded on two sides by rivers. The Red River forms the west boundary of the districts and the smaller Seine River forms the east boundary. The large portion of the two districts in close proximity to a water course indicated that stormwater separation (land drainage sewers) would be a viable stormwater management method. 
Another key feature of the district topography was a large depressed area, centrally located in the two districts, approximately bounded by Enfield Crescent. Ground elevations in the area were 2 to 3 metres lower than the surrounding area. The reason for the extreme (for Winnipeg) local relief was discovered on an early map of the area, found in a historical archive. The map, circa 1881, indicated the location of an oxbow of the Red River in the immediate area. Transposing the oxbow onto a current map shows that the low area falls within the oxbow (see Figure 15.5).

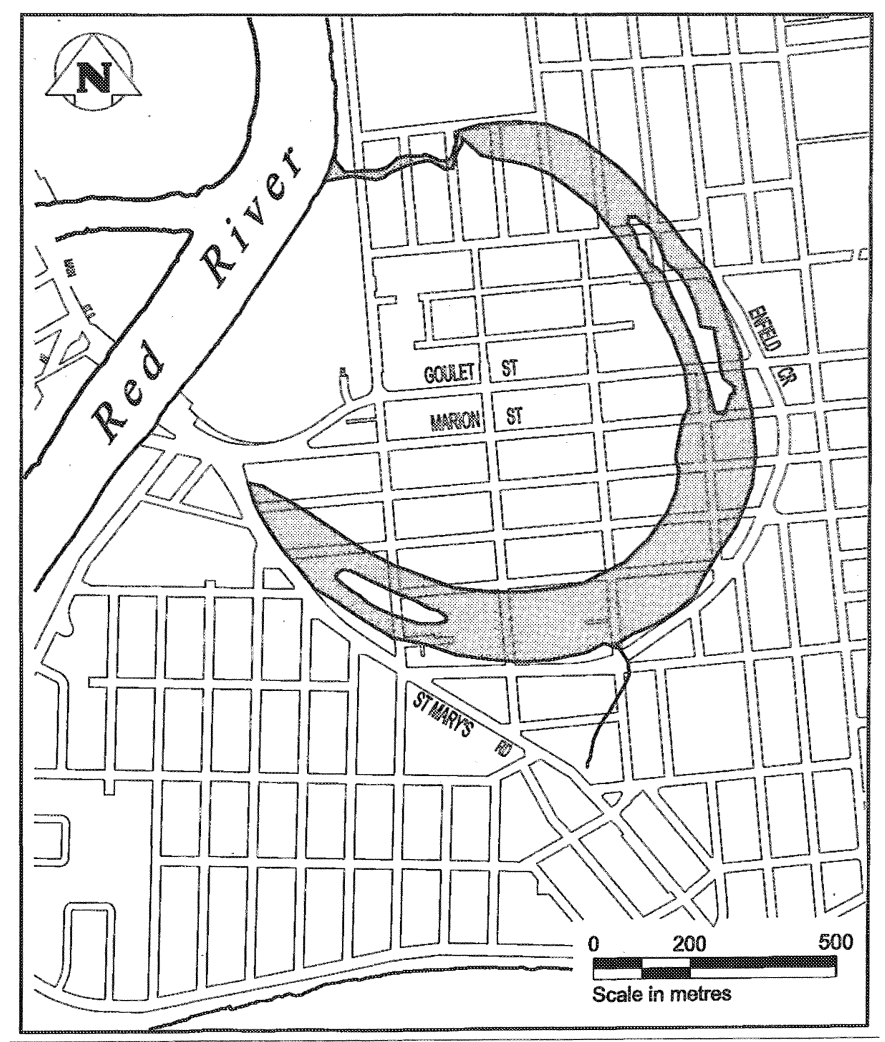

Figure 15.5 Location of historical Red River Oxbow.

At a number of locations in this area, the depth from ground to sewer invert was less than $2.5 \mathrm{~m}$. Considering that basements are typically $2 \mathrm{~m}$ deep, it was obvious that the combined sewer could not surcharge without potentially flooding basements. Furthermore, this limitation applied to any relief scheme conveying combined stormwater through the area. The situation indicated that 
wastewater separation, to disconnect the existing basements from the combined sewer system, would be a viable relief scheme for the depressed area. In this way, the capacity of the combined sewer could be dramatically increased by allowing sewer surcharge.

The review of the district topography indicated that all three major relief measures would be viable relief alternatives for the study area; however, before the start of the detailed relief analysis it was recognized, from past experience, that the relief works could be seriously impacted by site conditions.

\subsubsection{Site Conditions Affecting Implementation}

Site conditions can have a serious impact on implementation costs for relief works and, as a result, should be considered during the preliminary assessment of the various relief alternatives. Adverse subsurface conditions can limit the extent of, or in extreme cases, preclude certain relief measures. Furthermore, riverbank stability can be a serious issue in the selection of appropriate outfall locations and can result in extensive and costly rerouting of relief works to a more suitable outfall location at the detailed design stage. Consequently, the most cost-effective solution at the study phase may not prove to be the least costly to implement due to unknown site conditions.

Clearly the refinement of conceptual cost estimates for relief works implementation would benefit from a basic knowledge of conditions in the district. For the Marion and Despins project, a preliminary geotechnical investigation was developed to assess:

- overall subsurface conditions to determine the impact on sewer implementation costs; and

- riverbank assessment to determine suitable locations for outfalls, as well as locations that would require significant stabilization works.

The subsurface investigation (Dyregrov, 1999) consisted of drilling a number of testholes to determine general soil stratigraphy in the districts. The results indicated generally good conditions for pipe installations. Accordingly, it was assumed that subsurface conditions would not have a substantial impact on the preferred, or most cost-effective, relief measure regardless of the routing requirements.

The riverbank assessment entailed a visual examination of the potential outfall sites with respect to bank stability and potential stabilization requirements. While a solution to bank instability can usually be engineered, the solution is not always palatable to the area residents. The results of extensive 
riverbank stabilization can range from destruction of natural habitat to, in extreme cases, the need to acquire or expropriate adjacent lands. Accordingly, the suitability of a particular site is a major factor in the consideration of outfall location and therefore, influences any relief scheme requiring one or more outfalls, such as stormwater separation. The preliminary geotechnical analysis provided pertinent information at the development or formulation stage of the study. The analysis of potential sites in the Marion and Despins Districts resulted in the identification of several locations that were unsuitable for outfall implementation, and as a result, the routing requirements were accounted for during the study phase. Considering this information at the preliminary stage allows a more informed decision regarding conceptual costs.

\subsubsection{Recommended Relief System}

A number of different alternatives are typically developed for each basement flood relief analysis. Each alternative is conceptually designed and modeled to ensure that the system provides the required level of protection. A preliminary construction cost estimate is developed and the selection of a recommended system is then based on the most cost-effective solution.

As noted previously, the topography in the Marion and Despins Districts indicated that a number of different relief measures would be applicable to the sites. Several different relief alternatives were developed and it was noted that no single measure (i.e. storm relief sewers) could effectively provide area-wide relief due to the physical diversity of the districts.

Combinations of relief measures were investigated with the recommended relief works consisting of an amalgamation of relief measures including:

- Stormwater separation of most lands adjacent to the Red and Seine Rivers. Approximately 85 ha of stormwater contributing area in the two districts were separated from the combined sewer system.

- Wastewater separation of the low areas around the ancient Red River oxbow. This disconnects the basements from the CS system and increases the capacity of the combined sewers (by allowing sewer surcharge).

- Conventional parallel relief sewers to augment the capacity of the combined sewer systems at selected locations.

Locations of the recommended relief works in the Marion and Despins Districts are shown on Figure 15.6. 


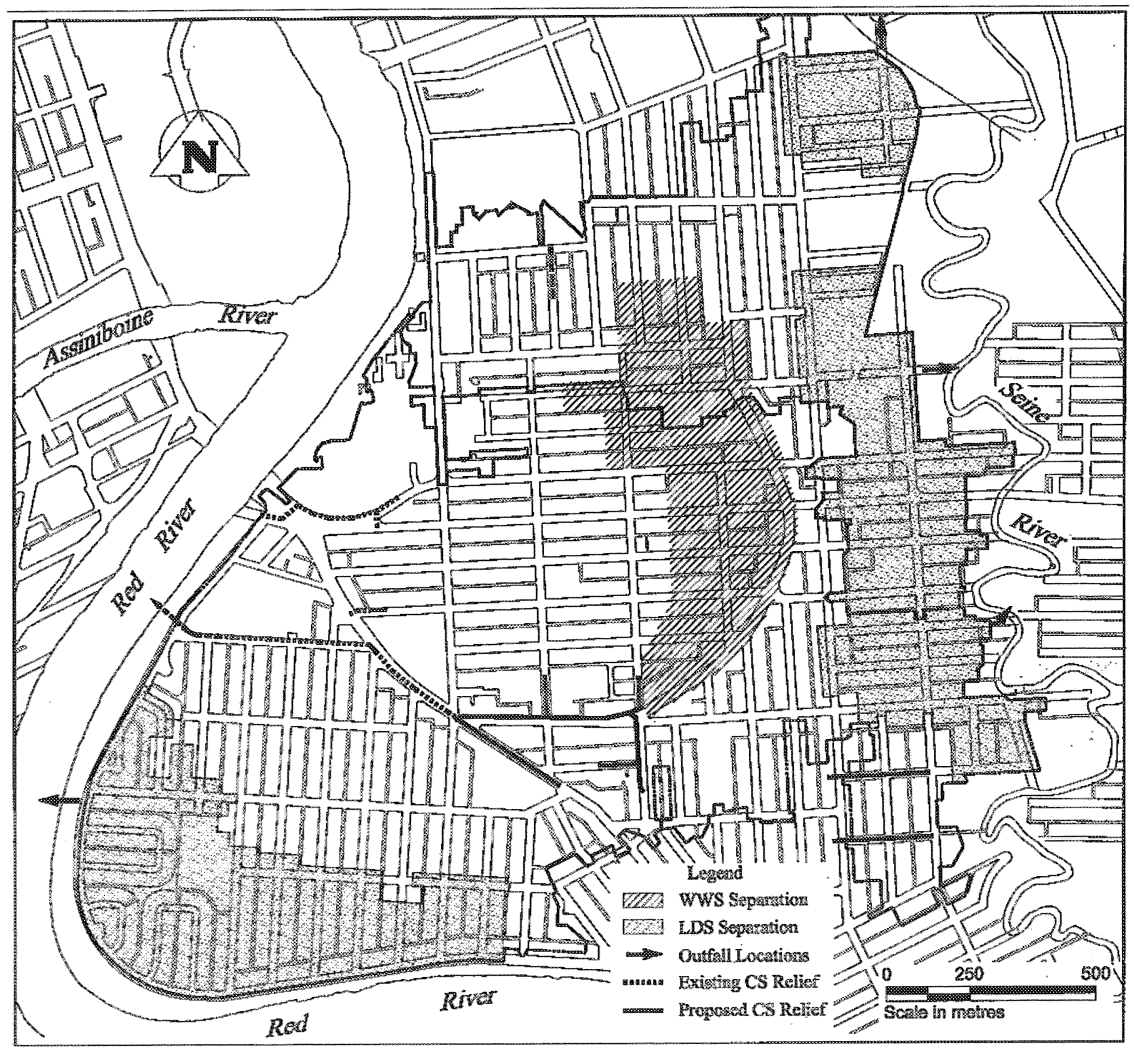

Figure 15.6 Recommended basement flood relief works in Marion and Despins districts.

\subsection{Integration Initiatives}

The City currently has two other major initiatives concerning the combined sewer system. The sewer renewal program deals with the rehabilitation and/ or renewal of the aging and deteriorating sewer system. The combined sewer overflow management plan seeks to reduce the number of combined sewer overflows to the rivers. Each program will require the outlay of a significant amount of public funds on an annual basis for the foreseeable future. The basement flood relief, sewer renewal, and CSO management programs deal with the same sewers and the relationship between the programs should be considered to provide the City with the greatest benefit. 


\subsubsection{Infrastructure Renewal}

Like many cities, Winnipeg is being forced to deal with an extensive infrastructure renewal program. Portions of the combined sewer system are over 120 $y$ old; however, the overall condition of the piping is not well known. The consequence of sewer failure ranges from service disruption due to sewer collapse to, in the most extreme conditions, large surface settlement and/or cave-ins. To revitalize this aging sewer system, the City has an ongoing program to upgrade the sewers on a priority basis. Upgrading priorities are developed from a sewer cleaning and CCTV inspection and defect coding program. This information is used to assess pipe structural condition using a newly-developed sewer management system model.

The type of sewer renewal is based on several factors including type and severity of pipe deterioration, residual damage from construction methods, and costs. Spot repairs are used to repair small, isolated problem areas. Repair techniques for longer sections, i.e. manhole to manhole, range from pipe lining (for pipes that retain their original shape) to on-line or off-line replacement for badly deteriorated pipes. It is the latter case, where an entire reach of pipe is being replaced, that offers the greatest opportunity for integration with the basement flood relief program.

The basement flood relief program, from its inception to present, has primarily resulted in the implementation of parallel relief sewers to augment the capacity of the existing combined sewer system. There have been instances where the basement flood relief works have been integrated with the sewer renewals, but this has been more by accident than by design. These cases have shown that constructing an oversized replacement pipe with adequate capacity for the design flows is more cost-effective than constructing a relief pipe and subsequent sewer renewal. In other words, one large pipe is usually cheaper to install than two smaller ones.

To assess the potential value of program integration requires a comparison of the cost of installing a parallel relief pipe and a future sewer renewal or replacement, to the cost of constructing an oversized replacement pipe. It is unfortunate that a program to identify sewer defects had not been carried out in the Marion and Despins Districts prior to the basement flood relief study. As a result, the following benefit analysis is largely academic in nature. It does, however, provide an insight into the potential financial benefits of integration.

\section{Marion and Despins District}

As noted previously, the topography in the districts resulted in separation works (land drainage and wastewater) being recommended for most of the relief works. Some parallel relief sewers were required; however, a large portion, 
including the relief trunk, had been installed under an earlier project. The remaining relief sewers were primarily under $900 \mathrm{~mm}$ in diameter. For this analysis, a reach of combined sewer in the Marion District was used as a test section.

The existing combined sewer is $600 \mathrm{~mm}$ in diameter and $94 \mathrm{~m}$ long. Basement flood relief requires a parallel relief pipe that is also $600 \mathrm{~mm}$ in diameter. A SWMM analysis was carried out and determined that a $900 \mathrm{~mm}$ sewer would be required, as an alternative, to replace the existing sewer and the proposed relief pipe.

Cost estimates for comparison purposes were based on current construction tenders received by the City. The analysis investigated both types of sewer renewal; relining the existing pipe and complete replacement with the same size pipe; however, for the existing diameter $(600 \mathrm{~mm})$ the costs are basically the same:

- $600 \mathrm{~mm}$ diameter sewer renewal/replacement $\$ 900 / \mathrm{m}$

- $600 \mathrm{~mm}$ diameter relief pipe installation $\$ 780 / \mathrm{m}$

- Total cost per metre, without program integration $\$ 1,680 / \mathrm{m}$

- $900 \mathrm{~mm}$ diameter sewer renewal $\$ 1,290 / \mathrm{m}$

- Potential savings through program integration $\$ 390 / \mathrm{m}$

This analysis shows that the potential savings for the test section amount to $\$ 390 / \mathrm{m}$, or $30 \%$. Savings of this magnitude justify a condition assessment of the existing sewer system prior to the commencement of basement flood relief studies. This would enable the basement flood relief works to consider sewer condition in developing relief alternatives and thoroughly assess the benefits of program integration.

\subsubsection{Combined Sewer Overflow Control Program}

The City of Winnipeg is currently in the preliminary stages of developing a proactive approach to control CSOs. The proactive approach has the potential for the development of an affordable CSO control program in partnership with the provincial regulators. This approach to CSO control provides the opportunity to develop and monitor the program as it evolves, with capability for future expansion of the controls.

The first step in any CSO control plan logically involves the enhancement of the existing system infrastructure. This would include:

- installation of interception and dewatering facilities in existing relief trunks to allow access to available latent storage (pipe storage below river level);

- modification of flow diversion rates;

- raising diversion weirs (in the combined sewer trunk) to increase inline storage; and 
- a monitoring program to assess current CSOs, as well as reductions over time.

The proposed CSO control approach also benefits from coordination with the basement flood relief program. The typical district relief involves the construction of a new relief trunk to convey WWFs to the river and/or stormwater separation. In the former case, relief works could be oversized to provide more inline storage and reduce overflow frequency. In the latter case, the reduction in stormwater entering the combined sewer system would enhance the available storage and result in less volume and potentially fewer overflows.

A generalized approach to integrating and optimizing CSO controls was developed for consideration with the basement flood relief program. The goal of the approach is to reach the specified target of four overflows per year (based on a typical year, 1992, rainfall). The first step is to determine the number of overflows in the existing system prior to the basement flood relief works. In the event that the existing system meets the overflow goal (unlikely), the CSO focus on the relief works would be to ensure that overflow frequency was not increased. The most likely scenario is that the existing system does not meet the overflow criteria.

Following the development of conventional relief works, the recommended system would be modeled to assess the impact on combined sewer overflows. If the overflow goal were attained, the need for an overflow control program in the district would be eliminated. The most likely scenario, however, is that additional control measures would be required.

This would initially consist of optimizing the existing combined sewer system (i.e. proactive control measures) by:

- raising diversion weirs to increase inline storage;

- accessing latent storage (available storage below river level in CS and SRS trunks); and

- maximizing inline storage (to trunk sewer obvert or to allowable level for basement flood prevention, whichever is lower).

These measures would then be modeled to determine their impact on achieving the control target of four overflows. The need for further controls to reach the target would require a review of the more structurally intense options such as:

- off-line storage;

- selective sewer separation;

- potential integration with infrastructure renewal (oversizing for additional storage); and

- modification to recommended relief works. 
This analysis would be used to identify the most promising option, or combination of options for CSO control. This would then lead to the development of a recommended plan for basement flood relief (near-term) and combined sewer overflow control (long-term) implementation. A flow chart of the generalized approach is shown in Figure 15.7.

\section{Marion and Despins Integration}

The foregoing approach was used in assessing the impact of the basement flood relief works on CSOs and the potential integration of the two programs. The existing situation (prior to implementation of relief works) had been reviewed as part of Winnipeg's CSO study with an estimated 18 overflows on an annual basis (Wardrop and Tetres, 1998). The CSO study also proposed a runoff based interception or diversion rate of $0.28 \mathrm{~m}^{3} / \mathrm{s}$. Proportioning the peak rate by contributing area resulted in flow diversion rates of 0.186 and $0.064 \mathrm{~m}^{3} / \mathrm{s}$ for the Marion and Despins Districts, respectively.

The first step in this analysis consisted of calculating the volumes of storage in the existing and proposed CS and SRS piping. The pipe data (size, length, invert elevations) was imported to a spreadsheet to calculate the pipe storage under a given elevation. The results are shown in Table 15.1.

Table 15.1 Inline storage volumes under a given elevation.

\begin{tabular}{clrr}
$\begin{array}{c}\text { Elevation } \\
(\mathrm{m})\end{array}$ & Description & \multicolumn{2}{c}{ Storage Value } \\
\hline & & Despins $\left(\mathrm{m}^{3}\right)$ & Marion $\left(\mathrm{m}^{3}\right)$ \\
223.7 & Normal river level (latent storage) & 520 & 1378 \\
224.0 & Obvert of Despins CS Trunk & 814 & 2478 \\
224.3 & Obvert of Marion CS Trunk & - & 3835 \\
\hline
\end{tabular}

The 1992 rainfall had been identified as the "typical year" based on the number and size of the rainfall events, and was used for this analysis. The hourly rainfall data was input to the SWMM Runoff Block, which had been revised to remove subcatchments proposed for stormwater separation (in the recommended flood relief plan).

A continuous simulation, using the SWMM Transport Block, was used to model the number and volume of overflows in each district. The transport model used the piping system developed for the Extran analysis of the basement flood relief works with some additions to account for inline storage and flow diversions. The volume of latent (below river level) and potential inline storage was modeled as a storage node. All overflow sewers were routed to the storage node. The flow out of the storage node was set to match the peak diversion 

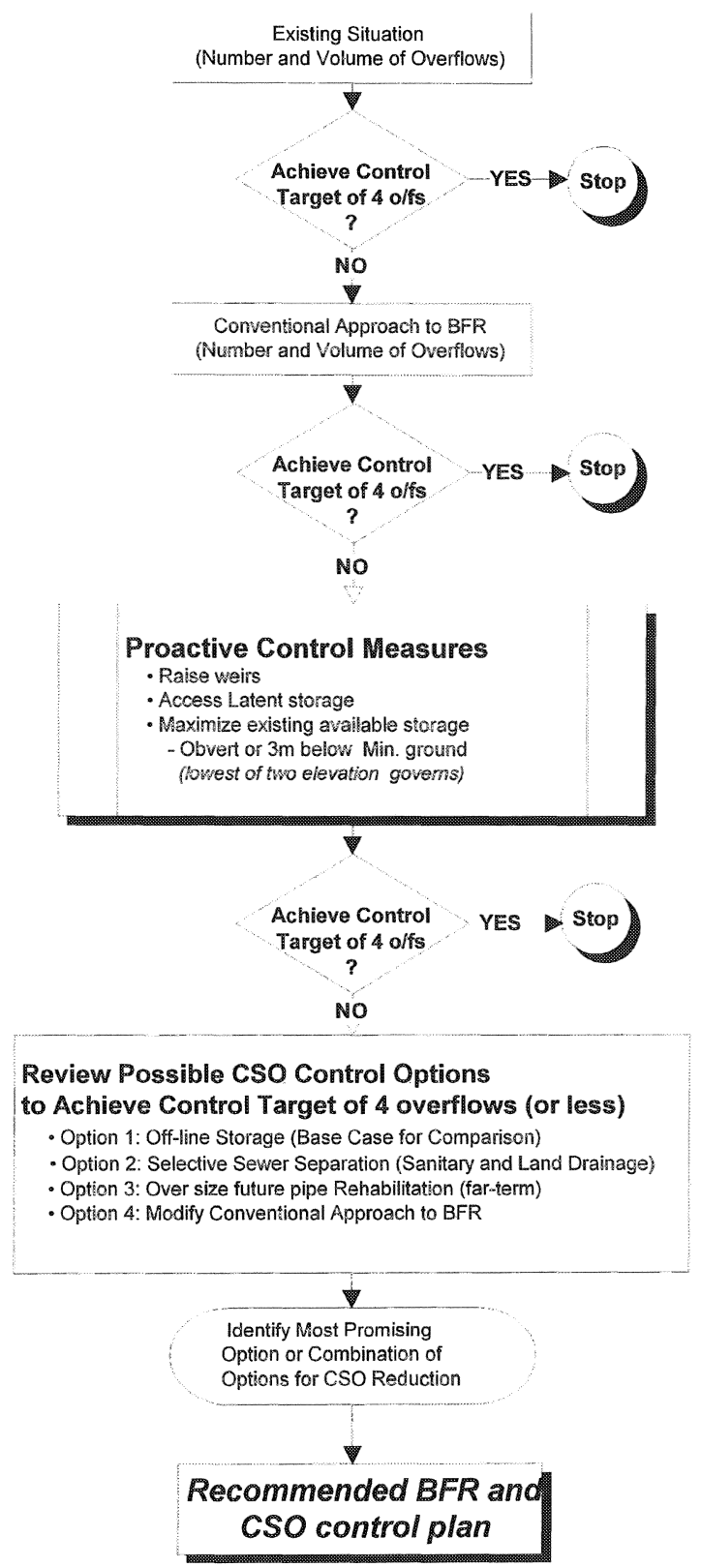

Figure 15.7 Generalized approach to integrating and optimizing basement flood relief with CSO control. 
rate until the event volume exceeded the storage volume. The flow out of the storage node was then set to match the rate of inflow from the combined trunk sewers. A flow divider, downstream of the storage node, modeled the flow diversion to the treatment facility and overflows to the river. All flows under the peak diversion capacity were diverted to the primary (to treatment) conduit. All flows over the diversion capacity were diverted to the secondary conduit and identified as overflows to the river system. The SWMM Statistics Block was then used to analyze the flows in the secondary, or overflow conduit. A graphic representation of the downstream portion of the Transport model is shown in Figure 15.8.

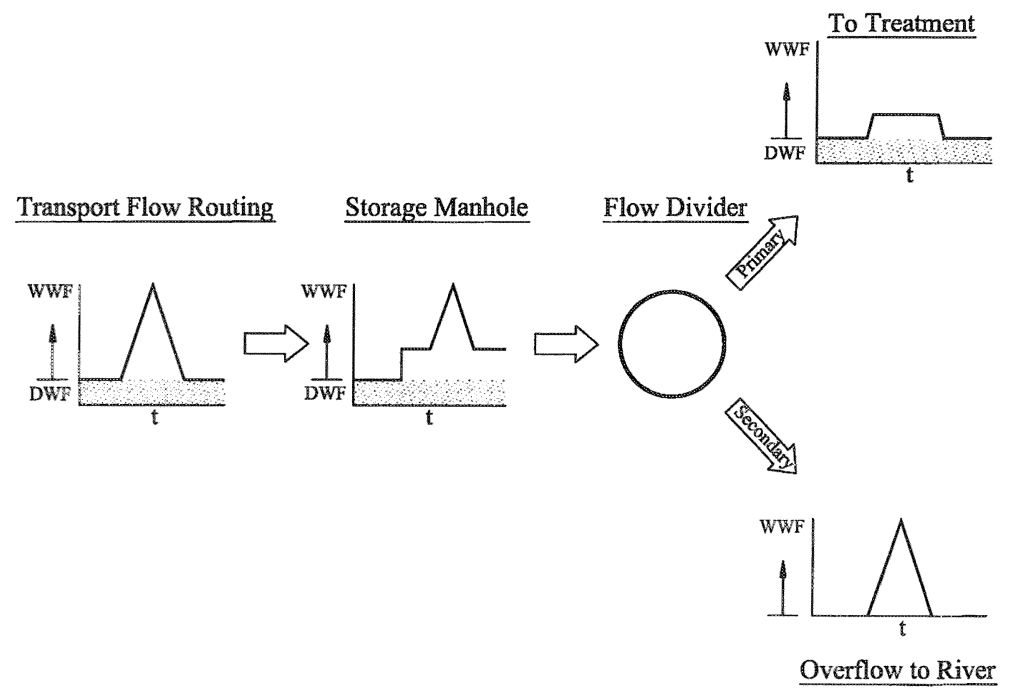

Figure 15.8 SWMM Transport model schematic.

The impact of the basement flood relief works on the computed total number of CSOs in the Marion and Despins Districts is shown in Table 15.2, with the additional storage required to reduce the number of annual overflows to four.

Table 15.2 Computed CSOs after basement flood relief implementation.

\begin{tabular}{ccccc} 
District & $\begin{array}{c}\text { Inline Storage Level } \\
\text { and Volume } \\
(\mathrm{m} / \mathrm{cu} . \mathrm{m})\end{array}$ & $\begin{array}{c}\text { Number } \\
\text { of } \\
\text { Overflows }\end{array}$ & $\begin{array}{c}\text { Overflow } \\
\text { Volume }\left(\mathrm{m}^{3}\right)\end{array}$ & $\begin{array}{c}\text { Additional } \\
\text { Storage for 4 } \\
\text { Overflows }\left(\mathrm{m}^{3}\right)\end{array}$ \\
\hline Despins & $223.7 / 520$ & 15 & 12,242 & 1,180 \\
& $224.0 / 814$ & 11 & 9,401 & 916 \\
Marion & $223.7 / 1,378$ & 16 & 50,477 & 4,333 \\
& $224.0 / 2,478$ & 12 & 40,637 & 3,800 \\
& $224.3 / 3,835$ & 10 & 27,773 & 2,590 \\
\hline
\end{tabular}


The basement flood relief works have an impact on CSOs, and with the implementation of inline storage, could reduce the number of overflows to 11 and 10, respectively, in the Despins and Marion Districts. While this is a substantial reduction from the current estimate of 18 overflows per year, it still does not reach the City's overflow target of four per year. Therefore, a range of control options was reviewed for a potential integrated approach to develop a basement flood relief and CSO control plan.

The basement flood relief program provides the greatest opportunity for CSO control by:

- increasing the size of relief pipes to provide additional inline storage; and

- additional separation works to reduce the volume of stormwater entering combined sewer relief system.

The most common option for implementing CSO controls would likely entail oversizing relief works, particularly trunk sewers, to increase inline storage. Unfortunately, this was not an option in the Marion and Despins Districts since the relief trunk had been previously installed and most relief sewers were too high to provide inline storage. Therefore, the impact of additional selective separation was reviewed.

Two areas were identified as having good potential for additional separation. In the Despins District, a 17.4 ha area adjacent to the Red River was reviewed. In the Marion District, the potential to increase a proposed land drainage sewer separation area by 25.3 ha was investigated. The two sites are identified on Figure 15.9.

The district contributing areas were revised to account for the potential separation works and the impacts determined with the SWMM model (see Table 15.3).

Table 15.3 Computed CSOs after basement flood relief implementation and additional stormwater separation.

\begin{tabular}{lccccc}
\hline District & $\begin{array}{c}\text { Inline Storage } \\
\text { Level and Volume } \\
\left(\mathrm{m} / \mathrm{m}^{3}\right)\end{array}$ & $\begin{array}{c}\text { Number } \\
\text { of } \\
\text { Overflows }\end{array}$ & $\begin{array}{c}\text { Additional } \\
\text { Storage for } 4 \\
\text { Overflows } \\
\left(\mathrm{m}^{3}\right)\end{array}$ & $\begin{array}{c}\text { Overflow Reduction } \\
\text { Due to Additional } \\
\text { Separation }\end{array}$ \\
\hline Despins & $223.7 / 520$ & 8 & 319 & 7 & 861 \\
& $224.0 / 814$ & 6 & 64 & 5 & 852 \\
Marion & $224.0 / 2,478$ & 11 & 2,980 & 1 & 830 \\
& $224.3 / 3,835$ & 8 & 1,770 & 2 & 820 \\
\hline
\end{tabular}




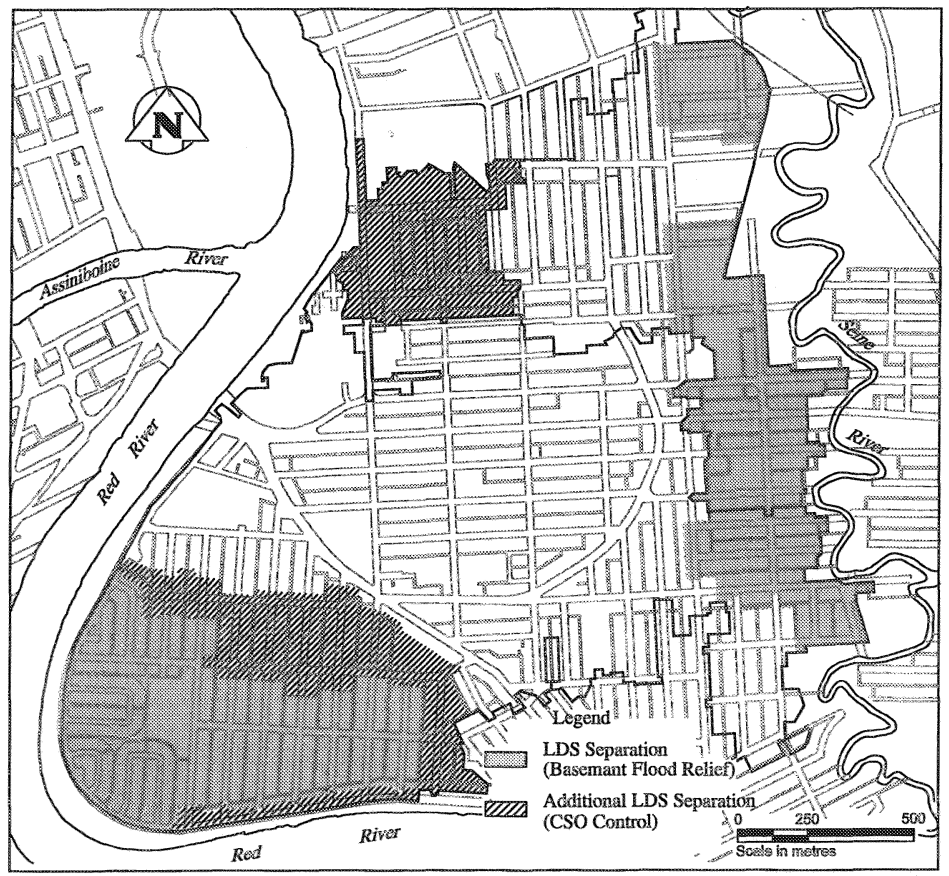

Figure 15.9 Additional separation areas reviewed for possible CSO control.

The impact of the additional stormwater separation is most apparent in the Despins District. The additional separation, in conjunction with the available inline storage, reduced the annual overflows from eleven to six and could be reduced to four with an additional $64 \mathrm{~m}^{3}$ of storage. This additional volume could be obtained through offline storage; however, potential integration with the infrastructure renewal program could also be used to achieve the overflow goal.

To compare the potential CSO control options, a preliminary cost estimate was carried out. The estimate compared the cost of the stormwater separation works to the cost savings form the reduction in offline storage.

Table 15.4 CSO control option cost comparison.

\begin{tabular}{lcc}
\hline District & Additional Separation $(\mathrm{ha} / \$)$ & Offline Storage Reduction $\left(\mathrm{m}^{3} / \$\right)$ \\
\hline Despins & $17.4 / 1,200,000$ & $852 / 950,000$ \\
Marion & $25.3 / 1,500,000$ & $820 / 910,000$ \\
\hline
\end{tabular}


The foregoing comparison indicates that the cost of additional separation does not quite offset the reduction in storage and therefore, the offline storage is the least cost method of achieving the CSO control target of four overflows per year. This should be reviewed in the Despins Districts in conjunction with the infrastructure renewal programs to determine the potential to oversize, or lower, sewer renewal works to increase inline storage. In this event, offline storage and associated pumping costs would be eliminated and a lifecycle cost analysis required to select the preferred district CSO control plan.

\subsection{Conclusions}

In the past, the basement flood relief program has been designed to meet a clearly defined scope of work to upgrade the level of flood protection in the CS districts. The implementation of the relief works requires the expenditure of considerable public funds. Two other City initiatives, the infrastructure renewal and CSO management programs, also deal with the combined sewers and public funding. The public's growing expectation of an integrated and costeffective approach to all infrastructure improvements results in the need for a new model for relief works.

This chapter describes a potential model for enhancing and integrating the Basement Flood Relief (BFR) program with other City initiatives. It is recognized that the previously developed methodology was well suited to meet the programs goals; however, these goals are changing. The new model is enhanced by additional effort during the study phase to provide more informed decision making. These enhancements include:

- preliminary geotechnical investigation of subsurface conditions in the district to identify impacts to the development of a preferred reliefalternative;

- preliminary investigation of riverbank stability at potential outfall locations for consideration during relief plan development; and

- sewer condition assessment to better consider integration of the infrastructure renewal program with the relief works.

The new model also includes a general approach to integrating and optimizing the relief works with the CSO control program. The approach was tested in the Marion and Despins Sewer Districts to assess the impact of the relief works on reducing overflows. It also identified the most cost-effective combination of relief works and CSO control plans to achieve the control target of four overflows per year. 


\section{References}

Dyregrov Consultants, 1999. Preliminary Geotechnical Investigation for Marion and Despins Sewer Relief Project.

Girling, R. and Sharp, E. 1986. City of Winnipeg, Basement Flooding Relief Program Review - 1986, Technical Discussion.

Huber, W. and Dickinson, R. 1988. Stormwater Management Model, Version 4: User's Manual, Environmental Research Laboratory, Office of Research and Development, U.S. Environmental Protection Agency, Athens, Ga. pp. 88-90.

Reid Crowther \& Partners Ltd. 1996. Marion/Despins Combined Sewer Districts Combined Sewer Relief Study.

Steiss, G., R.J. Gladding and E.J. Sharp. 1998. "CSO Management Study: Inline Storage vs. Basement Flood Protection in Combined Sewer Systems." Journal of Water Management Modeling R204-16. doi: 10.14796/JWMM.R204-16.

Wardrop Engineering Inc. 1985. Conceptual Design Report for Munroe, Roland and Hart, Combined Sewer Relief Study, pp. 13-14.

Wardrop Engineering Inc. and Tetres Consultants Inc. 1995. Combined Sewer Overflow Management Study, Phase 2 Technical Memorandum No. 2, Infrastructure/Treatment.

Wardrop Engineering Inc. and Tetres Consultants Inc. 1995. Combined Sewer Overflow Management Study, Phase 2 Technical Memorandum No. 3, Control Alternatives/Experience Elsewhere.

Wardrop Engineering Inc. and Tetres Consultants Inc. 1998. Combined Sewer Overflow Management Study, Phase 3 Technical Memorandum No. 1, Control Alternatives. 